\title{
Letter to the Editor / Reply
}

\section{Respirition}

Published online: June 28, 2018

Respiration 2018:96:206

DOI: $10.1159 / 000490339$

\section{Author's Reply \\ Erik H.F.M. van der Heijden \\ Department of Pulmonary Diseases (614), Radboud University Medical Center, Nijmegen, The Netherlands}

\section{Dear Colleagues,}

Thank you for your response and critical comments regarding the lack of long-term follow-up and success rate of endobronchial treatment for typical carcinoids.

I agree that the new evidence presented in this journal by Reuling et al. [1] does not yet warrant a radical change in the treatment of all patients with a typical carcinoid, and indeed the long-term outcome is not presented in this large single-center study. As with every invasive treatment, patient selection is an inevitable bias, and this study does not outperform surgical treatment in general.

What I have tried to argue in my editorial comment accompanying this study is that these new results add to a growing body of evidence supporting the role of endobronchial treatment [2]. Above all, each of these (often young) patients should be offered a critical appraisal and a careful evaluation of the potential treatment options, such that the patient is able to choose the best-fitting alternative. Careful selection is key for success in any form of treatment. When an endobronchial treatment is offered, I explain to my patients that this - in contrast to radical surgery - per defini- tion will result in a $\mathrm{R} 1$ resection with a microscopically residual tumor for which local cryotherapy will be applied. This must then be followed carefully and intensively for 10 years (with a combination of contrast computed tomography and high-definition bronchoscopy with repeat biopsies of the resection margins). With this careful follow-up and patient selection, there is a distinct role for the endobronchial treatment of typical carcinoids. In selected patients, a surgical resection may thus be prevented, and in many other cases, endobronchial debulking may improve the clinical status prior to radical surgery (in case of postobstructive pneumonia) and/or limit the extent of lung parenchyma resection. By a close cooperation between the interventional pulmonologist and the surgeon, in our experience, very good results can be obtained. My general advice is to consult, or refer, patients with bronchial carcinoids to a reference center with an experienced multidisciplinary team that includes experienced interventional pulmonologists and surgeons with experience in central-airway surgery.

However, I do agree that further research is needed and I would welcome an international multicenter retrospective analysis of all endobronchially and surgically treated patients with carcinoids and prospective multicenter trials to collect additional information to improve patient selection and international guidelines.

\section{References}

1 Reuling EMBP, Dickhoff C, Plaisier PW, Coupé VMH, Mazairac AHA, Lely RJ, Bonjer HJ, Daniels JMA: Endobronchial treatment for bronchial carcinoid: patient selection and predictors of outcome. Respiration 2018;95:220-227.

2 van der Heijden EHFM: Bronchial carcinoid? Interventional pulmonologist first! Respiration 2018;95:217-219.

\section{KARGER}

E-Mail karger@karger.com www.karger.com/res
(C) 2018 The Author(s)

Published by S. Karger AG, Basel

Karger

Open access

This article is licensed under the Creative Commons AttributionNonCommercial-NoDerivatives 4.0 International License (CC BY NC-ND) (http://www.karger.com/Services/OpenAccessLicense). Usage and distribution for commercial purposes as well as any distribution of modified material requir
Erik H.F.M Heijden

Department of Pulmonary Diseases (614) Radboud University Medical Center, P.O. Box 9101 NL-6500 HB Nijmegen (The Netherlands) erivanderheijden@ radboudumc.nl 